\title{
QUEEN'S
UNIVERSITY
BELFAST
}

\section{Change in psychological distress in longer-term oesophageal cancer carers: are clusters of illness perception change a useful determinant?}

Graham, L., Dempster, M., McCorry, N., Donnelly, M., \& Johnston, B. T. (2016). Change in psychological distress in longer-term oesophageal cancer carers: are clusters of illness perception change a useful determinant? Psycho-oncology, 25(6), 663-669. https://doi.org/10.1002/pon.3993

Published in:

Psycho-oncology

Document Version:

Peer reviewed version

Queen's University Belfast - Research Portal:

Link to publication record in Queen's University Belfast Research Portal

\section{Publisher rights}

Copyright @ 2015 John Wiley \& Sons, Ltd.

This is the peer reviewed version of the following article: Graham, L., Dempster, M., McCorry, N. K., Donnelly, M., and Johnston, B. T. (2016) Change in psychological distress in longer-term oesophageal cancer carers: are clusters of illness perception change a useful determinant? Psycho-Oncology, 25: 663-669, which has been published in final form at http://onlinelibrary.wiley.com/doi/10.1002/pon.3993/abstract. This article may be used for non-commercial purposes in accordance with Wiley Terms and Conditions for Self-Archiving.

\section{General rights}

Copyright for the publications made accessible via the Queen's University Belfast Research Portal is retained by the author(s) and / or other copyright owners and it is a condition of accessing these publications that users recognise and abide by the legal requirements associated with these rights.

\section{Take down policy}

The Research Portal is Queen's institutional repository that provides access to Queen's research output. Every effort has been made to ensure that content in the Research Portal does not infringe any person's rights, or applicable UK laws. If you discover content in the

Research Portal that you believe breaches copyright or violates any law, please contact openaccess@qub.ac.uk. 


\title{
Change in psychological distress in longer-term oesophageal cancer carers: are clusters of illness perception change a useful determinant?
}

\author{
Lisa GRAHAM ${ }^{1}$, Martin DEMPSTER ${ }^{1}$, Noleen K. MCCORRY ${ }^{2}$, Michael DONNELLY ${ }^{3}$, \\ \& Brian T. JOHNSTON ${ }^{4}$
}

\author{
${ }^{1}$ School of Psychology, Queen's University Belfast \\ ${ }^{2}$ Marie Curie Cancer Care Belfast
}

${ }^{3}$ Centre of Excellence for Public Health, Queen's University Belfast

${ }^{4}$ Department of Gastroenterology, Royal Victoria Hospital Belfast

Short form title: Distress and illness perceptions in oesophageal cancer carers

Corresponding author: Martin Dempster, School of Psychology, Queen's University Belfast, University Road, Belfast BT7 1NN, Northern Ireland. Email; m.dempster@qub.ac.uk

Sponsors: This research was supported by a grant from Action Cancer, Northern Ireland and facilitated by the Oesophageal Patients' Association UK. 
Psychological distress in carers

\section{Abstract}

Objective: This study provides a longitudinal assessment of distress in longer-term oesophageal cancer carers, while examining illness perception schema as a possible determinant of change in distress over time.

Methods: Oesophageal cancer carers $(n=171), 48$-months post-diagnosis, were assessed at baseline and 12-months later with the Illness Perception Questionnaire-Revised, Cancer Coping Questionnaire, Hospital Anxiety and Depression Scale and Concerns About Recurrence Scale.

Results: Findings report deterioration from normal to probable anxiety in $35.7 \%$ of carers and probable depression in $28.7 \%$ carers over time. Fear of recurrence remained stable. Changes in control, consequence and cause beliefs were identified as key determinants of a change in psychological morbidity.

Conclusions: Illness beliefs appear to be valuable targets for psychological intervention to improve wellbeing among carers of people with oesophageal cancer.

Keywords: cancer; oncology; oesophagus; carers; anxiety; depression 
Psychological distress in carers

\section{Background}

Despite widespread acknowledgement of cancer carers as "secondary survivors" reporting equivalent levels of psychological morbidity to survivors [1], there is a relative dearth of attention given to the psychological sequelae from caregiving [2;3]. This is an important gap in the literature, as carer stress is often considered to have an impact on patient outcomes [4]. Oesophageal cancer carers have received little research attention yet align to an increasingly prevalent survivor group [5]. Oesophageal cancer carers face a myriad of challenges typical of caring for survivors of a gastro-intestinal cancer, including a poor prognosis [6] and a significant, lasting impact on quality of life [7].

Levels of psychological morbidity in this carer population are largely unknown, with only two relevant studies [8;9]. One study demonstrated that $71 \%$ of carers would benefit from formal mental health care [8]; the other demonstrated $30 \%$ of carers report moderate/high levels of anxiety, 10\% report moderate/high levels of depression, and significant levels of fear of recurrence [9]. Both studies are cross-sectional in design and, as with the majority of cancer carer research, involve people who have been carers for a relatively short time [10]. Longitudinal studies are needed to examine change in psychological distress so that supportive care needs may be met across the illness trajectory [11].

Possible key determinants of psychological distress in oesophageal cancer carers are illness perceptions, as conceptualised by Leventhal's Common-Sense Model [CSM;12]. Illness perceptions are the cognitive and emotional representations of illness held by an individual. The CSM suggests that an individual will attempt to assign meaning to an illness via their perceptions about the illness. In an effort to restore normal functioning, individuals will develop coping strategies (based on their illness perceptions), which will then be evaluated in terms of their success in restoring equilibrium. The result of this evaluation may be a change in coping strategy and/or a change in perceptions about the illness. In summary, the model suggests that a person's perceptions about an illness and their coping strategies can have an impact on their psychological well-being.

A previous cross-sectional study of oesophageal cancer carers reported that illness perceptions accounted for the majority of explained variance in anxiety, depression, and fear of recurrence [9]. Psychological distress was higher in carers who believe that (i) the illness is more acute and cyclical in pattern, (ii) the survivor has a poor understanding of their condition, and (iii) serious consequences await both the survivor and themselves. 
Psychological distress in carers

Several illness perception interventions have shown promise in reducing psychological morbidity in carer populations [13;14]. Although previous research [9] is useful in identifying which illness perceptions are associated with psychological distress at one point in time, development of an intervention modifying illness perceptions requires evidence that a change in illness perceptions corresponds to a change in levels of psychological distress. The majority of longitudinal designs predict an outcome at follow-up from illness perceptions at baseline [15]. Studies moving beyond a prediction model have done so by identifying individuals sharing collections of illness beliefs which change in a similar way over time [16;17]. This method of studying illness perception 'schema' [18] has various benefits, not least the conceptual relevance to the CSM of studying a collection of beliefs as opposed to single illness perceptions in isolation. No other study has used cluster analysis to identify groups of carers sharing illness perception schema and provide a longitudinal assessment of psychological distress in this population.

The present research aims to: (i) provide a longitudinal assessment of anxiety, depression and fear of recurrence in longer-term oesophageal cancer carers and to (ii) determine if subgroups of oesophageal cancer carers share schema reporting similar change over time, and if these schema are useful in predicting change in psychological distress.

\section{Methods}

Oesophageal cancer survivors registered on the Oesophageal Patient's Association (OPA) database were invited, by post, to give a questionnaire pack to their carer, i.e. a partner/relative/friend they identified as being their main source of emotional and physical support. To be eligible to participate, the survivor needed to have undergone oesophagectomy for oesophageal cancer. A second identical questionnaire pack was mailed to the carers approximately 12 months later.

Ethical approval for the study was gained from the University Ethics Committee, Queen's University Belfast.

The questionnaire pack included the following measures - 
Psychological distress in carers

Demographic and health related items - gender, age, relationship to survivor, geographic region, living arrangement, employment status, time since cancer diagnosis and whether or not the survivor had any comorbidities.

Anxiety and Depression - the 14-item Hospital Anxiety and Depression Scale [HADS;19] assesses levels of generalised anxiety and depression. Responses are on a Likert scale, higher scores indicating higher symptom frequencies (subscale range 0-21). The following scores indicate the degree to which a respondent might be a clinical 'case' [19]; normal $(<8)$, possible (8-10) and probable clinical anxiety or depressive case (11-21). The HADS has been validated among clinical and non-clinical populations [20;21].

Fear of Recurrence - the 4-item Concerns About Recurrence Scale- Part 1 (CARS;22) assesses overall fear of recurrence; frequency, potential for upset, consistency and intensity of fears. Responses are given on a Likert scale from 1 to 6 , with higher total scores indicating a greater fear of recurrence. The scale has good evidence for reliability and validity $(23 ; 24)$. Carers were asked about their fear of cancer recurrence for the survivor (Cronbach's alpha = $0.90)$.

Coping Strategies - the 21-item Cancer Coping Questionnaire [CCQ;25] assesses coping strategies used in the previous week: interpersonal support, reflection/relaxation coping, diversion, planning, and positive focus. Responses are on a 1-4 Likert scale. Higher scores indicate greater use of a coping strategy. There is good evidence for reliability and validity [25]. Carers were asked about how they cope with the survivor's cancer (Cronbach's alpha = 0.70 to 0.89$)$.

Illness Perceptions - the Illness Perception Questionnaire-Revised [IPQ-R;26] measures a respondent's beliefs about illness: cause of illness, timeline acute or chronic, timeline cyclical or episodic, consequences of illness, personal control, treatment control and illness coherence. A modified version of the IPQ-R [27] is used to address the illness perceptions of personal control, consequences and illness coherence from the perspective of both the carer and survivor. Further information on the modifications made for carers has been reported previously $[9,28]$. Responses are on a Likert scale (1 to 5), with higher scores representing stronger beliefs. To assess perceived cause, an open-ended item asks respondents to state the three main causes of the survivor's condition. Similar to previous research [9], the data on perceived causes from the current sample were subjected to factor analysis revealing three factors; emotional causes (e.g. stress), behavioural causes (e.g. 
Psychological distress in carers

smoking), and external causes (e.g. fate), explaining $44 \%$ of the total variance. The IPQ-R has considerable evidence to support its reliability and validity, including among oesophageal cancer survivors [29]. In this study, Cronbach's alpha for the scales on the carer's version of the IPQ-R ranged from 0.77 to 0.90 .

\section{$\underline{\text { Statistical Analysis }}$}

Statistical analysis was conducted in SPSS (version 21).

Change scores were calculated by subtracting the second time point score from the first time point score. Cluster analysis was applied to the standardised IPQ-R change scores, to identify participants whose illness beliefs changed in a similar way. The two-stage method used is that of Milligan [30] identified by Clatworthy and colleagues [18] as being the optimum for illness perception research. Firstly a hierarchical cluster analysis (Ward's clustering method) was used to identify the number of clusters, with squared Euclidean distance as the similarity measure. By observing the dendrogram and the agglomeration schedule, three clusters were identified as emerging from the data. The stability of clusters was validated by dividing the study sample in half and repeating the cluster analysis on each, with a similar three cluster structure emerging. The number of clusters and cluster centroids identified using the Ward's method were then entered into an iterative cluster analysis (Kmeans clustering method). Differences between clusters were assessed using ANOVA to assess differences in change scores.

Separate hierarchical regression analyses were conducted to construct a model of change in anxiety, depression and fear of recurrence. Demographic and medical variables were entered in the first block, with CCQ change scores and IPQ-R cluster membership entered in the second block. Demographic variables with more than 2 levels and IPQ-R cluster membership were entered as dummy variables.

\section{Results}

\section{Carer Characteristics}

A total of 379 carers returned their questionnaires at baseline, with 228 carers returning the survey at both time-points (40\% dropout rate over time) and after removing participants with missing data, complete data were provided by 171 carers. There was no significant difference 
Psychological distress in carers

on depression $(\mathrm{t}=1.99, \mathrm{p}=.05)$ or fear of recurrence $(\mathrm{t}=1.44, \mathrm{p}=.152)$ between the participants who provided complete data at both time points and the participants who provided data at time 1 only. Non-completers were significantly more anxious than completers $(\mathrm{t}=2.54$, $\mathrm{p}=.011$ ), but the effect size was small (Cohen's $\mathrm{d}=0.26$ ). The mean age of participants was 62.56 years $(\mathrm{SD}=10.05)$, predominantly female $(72.5 \%)$ and retired $(61.4 \%)$. The majority of participants were the survivor's spouse or partner $(96.49 \%)$, and represented a longer term survivor population who at inclusion in the study were 4 years post-diagnosis on average $(\mathrm{IQR}=2-7$ years $)$.

Do levels of psychological distress change over time in oesophageal cancer carers?

At baseline, carers reported a HADS Anxiety score of $\mathrm{M}=7.50(\mathrm{SD}=4.72)$ and a HADS Depression score of $\mathrm{M}=4.47$ ( $\mathrm{SD}=3.82$ ). At 12-month follow-up levels of anxiety $\mathrm{M}=14.44$ ( $\mathrm{SD}=4.84)$ and levels of depression $\mathrm{M}=11.41(\mathrm{SD}=3.99)$ had increased significantly, with a large effect size (anxiety $\mathrm{d}=1.45$ and depression $\mathrm{d}=1.78$ ) from baseline. Using the HADS clinical cut-off scores [19], 48.5\% (83/171) of the carer sample deteriorated from normal levels of anxiety into possible or probable anxiety. With depression there was a similar marked deterioration, with $67.3 \%(115 / 171)$ of the carers reporting normal levels of depression at baseline and possible/probable depression at 12 months. No improvements from probable to normal levels of psychological morbidity were reported.

Levels of fear of recurrence as assessed by the CARS remained relatively stable over time with no significant difference between baseline $\mathrm{M}=13.65$ ( $\mathrm{SD}=5.58)$ and follow-up $\mathrm{M}=13.97,(\mathrm{SD}=5.59)$.

Do subgroups of oesophageal cancer carers share illness perception 'schema' which report similar change over time?

Three distinct clusters emerged from the data. Mean difference scores are displayed in Table 1.

Cluster $1(n=79)$ represents a group of carers who display a marginal to moderate change in beliefs over time, increasingly believing the illness to be more acute and with a cyclical presentation of symptoms, and to have more severe consequences (for themselves and the survivor). These carers have increasingly strong causal beliefs, particularly belief in an emotional cause. 
Psychological distress in carers

Cluster $2(\mathrm{n}=26)$ represents a group of carers with most illness beliefs reporting a marked change over time. These carers report belief in an increasingly chronic condition, with an episodic presentation of symptoms and a lessening of (carer/survivor/treatment) control. They increasingly believe that they and the survivor understand the condition, and feel over time that there will be less severe consequences for themselves and the survivor. Over time their causal beliefs weaken.

Cluster $3(n=66)$ represents a group of carers who report marginal to moderate change including a decreasing belief in severe consequences for survivor and carer, an increase in the perception that the condition is acute and with a cyclical presentation of symptoms, and who report a marked increase in all control beliefs. The carers also increasingly feel they and the survivor do not understand the condition, and feel less strongly about the cause of the condition over time.

There was a significant difference in change in anxiety between the three clusters (see Table 1). Carers in cluster 1 reported a mean increase in anxiety over time, with anxiety decreasing in carers in clusters 2 and 3. Similarly, there was a significant difference in change in depression between the three clusters. Carers in cluster 1 reported a mean increase in depression over time, with depression decreasing in carers in cluster 2 and 3. Cluster 1 and 2 were distinct from each other in relation to change in anxiety and depression, with cluster 3 not significantly different in relation to change in anxiety or depression from either of the other two clusters. There was no significant difference in relation to change in fear of recurrence (CARS) between clusters.

All three clusters were distinguishable on several illness perception domains, each displaying a significant large effect between clusters: Personal Control (Survivor), Personal Control (Carer), and Illness Coherence (Carer).

Are illness perception clusters useful in predicting change in psychological distress over $\underline{\text { time? }}$

\section{Fear of Recurrence}

The covariates in the regression model explained a total of $16.3 \%$ of the variance in change in fear of recurrence, $\mathrm{F}(7,145)=1.129, \mathrm{p}=.004$. The first block (containing demographic and medical variables) accounted for $9.2 \%$ of variance in change FoR, with the second block 
Psychological distress in carers

(containing change in use of coping strategies and cluster membership) accounting for a further $7.1 \%$ of variance.

There were several significant predictors in the model (see Table 2). Cluster membership was the most significant predictor, with cluster 3 associated with a decrease in fear of recurrence over time in comparison to cluster 1. An increase in the use of interpersonal coping over time was another significant predictor, associated with an increase in fear of recurrence over time. No demographic or medical variables significantly predicted changes in fear of recurrence.

\section{Depression}

The covariates in the regression model explained a total of $26.4 \%$ of the variance in change in depression, $\mathrm{F}(7,145)=2.081, \mathrm{p}=.004$. The first block of the model accounted for $13.2 \%$ of variance in change in depression, with the second block accounting for a further $13.2 \%$ of variance.

There were several significant predictors in the model (see Table 3). Cluster membership was the most significant predictor, with both cluster 2 and cluster 3 associated with a decrease in depressive symptomology over time in comparison to cluster 1 . An increase in the use of positive focus over time was also a significant predictor of changes in depression levels, associated with a decrease in depression over time. No demographic or medical variables significantly predicted changes in depression.

\section{Anxiety}

The covariates in the regression model explained a total of $37.4 \%$ of the variance in anxiety change, $F(7,145)=3.466, p<.001$. The first block of the model accounted for $12.2 \%$ of variance in change in anxiety, with the second block accounting for a further $25.2 \%$.

There were several significant predictors in the model (see Table 4). An increase in the use of diversionary coping was the most significant predictor followed by relaxation/reflection coping, both associated with an increase in anxiety levels over time. An increase in positive focus coping strategies was associated with a decrease in anxiety over time. Cluster membership, in addition to demographic and medical variables, failed to significantly predict changes in anxiety. 
Psychological distress in carers

\section{Discussion}

This is the first study to provide a longitudinal assessment of psychological distress in oesophageal cancer carers over time. It has previously been established that this carer population experience significant levels of anxiety and depression [9]. This paper extends this knowledge further by demonstrating a concerning deterioration in the psychological wellbeing of longer-term carers (average 4 years post-diagnosis) across a one year time period.

In the cancer literature there is an inconsistent relationship between time and psychological distress [31], though distress of carers in a mixed-cancer sample has been reported to increase (between 6-months to 3-years post-diagnosis) to levels comparable to the current sample of oesophageal cancer carers [32]. However, there is a dearth of longitudinal assessment extending beyond 3 years post-diagnosis. Therefore, there is no similar research with which to compare the findings of the current sample. These findings do however align to a similar increase in distress in longer-term oesophageal cancer survivors [16], with an acknowledged relationship between distress in survivors and carers [31].

A regression model demonstrated that no demographic or medical variables were significant predictors of a change in psychological distress over time. Although previous cross-sectional research reported younger age to be associated with heightened anxiety and fear of recurrence [9], other factors appear to be responsible for fluctuations (deteriorations or improvements) in distress levels over time. Increasing positive focus appears to reduce anxiety and depression (which is not surprising). However, an increase in diversionary and relaxation coping styles is associated with an increase in anxiety. It might be that these coping strategies represent an aspect of avoidance, which might be beneficial in the short term, but ultimately does not address the underlying issue, so is likely to lead to longer-term anxiety. For fear of recurrence, the strongest predictor in the model was interpersonal coping. Carers who are more likely to engage in this type of coping are also more likely to report high levels of fear of recurrence. The finding suggests a need for carers to find alternative sources of social support as a coping mechanism, as they do not derive a benefit from seeking support from the oesophageal cancer survivor. This might be the result of putting the needs of the relative they care for above their own [33]. 
Psychological distress in carers

Cluster membership was found to be one of strongest covariates of change in fear of recurrence and change in depression over one year in longer-term carers. Three clusters emerged from the data. Cluster 1 represents an increasingly pessimistic group of carers, Cluster 2 represents an increasingly realistic, yet powerless group of carers and Cluster 3 represents an increasing hopeful and in control group of carers. These clusters represent meaningful sub-groups of helplessness/hopelessness, a dimension, which has been shown previously to be associated with distress [34]. Membership of clusters 2 and 3 was a significant predictor of reduction in depression over time. The distinguishable attribute from clusters 2 and 3 is a reduction in a belief of severe consequences for the survivor and carer over time, in addition to a reduction in causal beliefs. Membership of cluster 3 was a significant predictor of a reduction in fear of recurrence over time. The distinguishable attribute was an increase in control beliefs over time. In summary, it would appear beneficial to target the illness beliefs of consequences, cause and control in any prospective intervention.

There are several limitations with the current study. Firstly, most of the questionnaires were originally designed to be used with patients rather than carers. Although these questionnaires have been used previously with carers of oesophageal cancer survivors $[9,28]$ and show good levels of internal consistency in the current study, additional validation work with carer samples would be beneficial. Furthermore, there is some concern about whether the HADS measures anxiety and depression separately or general distress [35,36]. Secondly, illness perception clusters and coping strategies may be interpreted as explaining little variance in change in psychological distress. However, cluster membership was a better predictor of change in psychological distress than any medical or demographic variable and the levels of explained variance in psychological distress have occurred despite illness perceptions appearing to remain stable. Future research may measure change in illness perceptions and corresponding change in psychological distress over a more acute period (i.e. after diagnosis and through initial treatment). Finally, it is not possible to discern, from the current research, whether the change in coping or illness perceptions preceded the change in the outcome variables. Therefore, evidence is still needed that the active modification of illness beliefs is i) possible, and ii) will result in a change in psychological morbidity. A prospective intervention would provide this evidence. 
Psychological distress in carers

In conclusion, the present study has reported that psychological wellbeing in a sizeable proportion of longer-term oesophageal cancer carers deteriorates over the course of a year. Illness perception schema have been identified as a key determinant of this change, with enhancing control beliefs, lessening focus on illness cause, and setting realistic expectations for consequences key elements for a prospective intervention.

\section{Conflict of Interest Statement}

None of the authors have any conflicts of interest to report. 
Psychological distress in carers

\section{References}

1. Mitchell AJ, Ferguson DW, Gill J, Paul J, Symonds P. Depression and anxiety in long-term cancer survivors compared with spouses and healthy controls: a systematic review and meta-analysis. The lancet oncology 2013;14(8):721-732.

2. Mittelman M. Taking care of the caregivers. Current Opinion in Psychiatry 2005;18(6):633-639.

3. Kim Y, Kashy DA, Spillers R., Evans TV. Needs assessment of family caregivers of cancer survivors: three cohorts comparison. Psycho-Oncology 2010;19(6):573-582.

4. Donnelly N-A, Hickey A, Burns A, Murphy P, Doyle F (2015) Systematic Review and Meta-Analysis of the Impact of Carer Stress on Subsequent Institutionalisation of Community-Dwelling Older People. PLoS ONE 10(6): e0128213. doi:10.1371/journal.pone.0128213

5. Ries LAG, Eisner MP, Kosary CL, Hankey BF, Miller BA, Clegg L et al (eds). SEER Cancer Statistics Review, 1975-2002, National Cancer Institute. Bethesda, MD, http://seer.cancer.gov/csr/1975_2002/, based on November 2004 SEER data submission, posted to the SEER web site 2005.

6. Allum WH, Stenning SP, Bancewicz J, Clark PI, Langley RE. Long-term results of a randomized trial of surgery with or without preoperative chemotherapy in esophageal cancer. Journal of Clinical Oncology 2009;27(30):5062-5067.

7. Lagergren P, Avery KN, Hughes R, Barham CP, Alderson D, Falk SJ, et al. Healthrelated quality of life among patients cured by surgery for esophageal cancer. Cancer 2007;110(3):686-693.

8. Donnelly M, Anderson LA., Johnston BT, Watson RGP, Murphy SJ, Comber H et al. Oesophageal cancer: caregiver mental health and strain. Psycho-Oncology 2008;17(12):1196-1201.

9. Dempster M, McCorry NK, Brennan E, Donnelly M, Murray LJ, Johnston BT. Psychological distress among family carers of oesophageal cancer survivors: the role of illness cognitions and coping. Psycho-Oncology 2011;20(7):698-705.

10. Kim Y, Given BA. Quality of life of family caregivers of cancer survivors. Cancer 2008;112:2556-2568.

11. Stenberg U, Ruland CM, Miaskowski C. Review of the literature on the effects of caring for a patient with cancer. Psycho-Oncology 2010;19(10):1013-1025. 
Psychological distress in carers

12. Leventhal H, Meyer D, Nerenz D. The common sense representation of illness danger. Contributions to medical psychology 1980;2:7-30.

13. Broadbent E, Ellis CJ, Thomas J, Gamble G, Petrie KJ. Further development of an illness perception intervention for myocardial infarction patients: a randomized controlled trial. Journal of psychosomatic research 2009; 67(1): 17-23.

14. Song MK., Ward SE, Happ MB, Piraino B, Donovan HS., Shields AM et al. Randomized controlled trial of SPIRIT: An effective approach to preparing AfricanAmerican dialysis patients and families for end of life. Research in nursing \& health 2009; 32(3): 260-273.

15. Frostholm L, Oernboel E, Christensen KS, Toft T, Olesen F, Weinman J et al. Do illness perceptions predict health outcomes in primary care patients? A 2-year followup study. Journal of psychosomatic research 2007;62(2):129-138.

16. Dempster M, McCorry NK., Brennan E, Donnelly M, Murray LJ, Johnston BT. Do changes in illness perceptions predict changes in psychological distress among oesophageal cancer survivors?. Journal of health psychology 2011;16(3):500-509.

17. Kaptein AA, Bijsterbosch J, Scharloo M, Hampson SE, Kroon HM, Kloppenburg M. Using the common sense model of illness perceptions to examine osteoarthritis change: a 6-year longitudinal study.Health Psychology 2010;29(1):56.

18. Clatworthy J, Hankins M, Buick D, Weinman J, Horne R. Cluster Analysis in Illness Perception Research: A Monte Carlo Study to Identify the Most Appropriate Method. Psychology \& Health 2007; 22(2):123-142.

19. Zigmond AS, Snaith RP. The hospital anxiety and depression scale. Acta psychiatrica scandinavica 1983;67(6):361-370.

20. Luckett T, Butow PN, King MT, Oguchi M, Heading G, Hackl NA et al. A review and recommendations for optimal outcome measures of anxiety, depression and general distress in studies evaluating psychosocial interventions for English-speaking adults with heterogeneous cancer diagnoses. Supportive care in cancer 2010;18(10): 1241-1262.

21. Bjelland I, Dahl AA, Haug TT, Neckelmann D. The validity of the Hospital Anxiety and Depression Scale: an updated literature review.Journal of psychosomatic research 2002;52(2): 69-77.

22. Vickberg SMJ. The Concerns About Recurrence Scale (CARS): a systematic measure of women's fears about the possibility of breast cancer recurrence. Annals of Behavioral Medicine 2003;25(1):16-24. 
Psychological distress in carers

23. van den Beuken-van Everdingen M, Peters ML, de Rijke JM, Schouten HC, van Kleef M, Patijn J. Concerns of former breast cancer patients about disease recurrence: a validation and prevalence study. Psycho-Oncology 2008;17(11):1137-1145.

24. Thewes B, Butow P, Zachariae R, Christensen S, Simard S, Gotay C. Fear of cancer recurrence: a systematic literature review of self-report measures. Psycho-Oncology 2012; 21(6):571-587.

25. Moorey S, Frampton M, Greer S. The Cancer Coping Questionnaire: A self-rating scale for measuring the impact of adjuvant psychological therapy on coping behaviour. Psycho-Oncology 2003;12(4):331-344.

26. Moss-Morris R, Weinman J, Petrie K., Horne R, Cameron L, Buick D. The revised illness perception questionnaire (IPQ-R). Psychology and health 2002;17(1):1-16.

27. Barrowclough C, Lobban F, Hatton C, Quinn J. An investigation of models of illness in carers of schizophrenia patients using the Illness Perception Questionnaire. British Journal of Clinical Psychology 2001; 40(4): 371-385.

28. Dempster M, McCorry NK, Brennan E, Donnelly M, Murray LJ, Johnston BT. Illness perceptions among carer-survivor dyads are related to psychological distress among oesophageal cancer survivors. Journal of Psychosomatic Research, 2011; 70, 432439.

29. Dempster M, McCorry NK.. The factor structure of the revised illness perception questionnaire in a population of oesophageal cancer survivors. Psycho-Oncology 2012; 21 (5): 524-530.

30. Milligan GW. An examination of the effect of six types of error perturbation on fifteen clustering algorithms. Psychometrika 1980;45:325-342.

31. Hodges LJ, Humphris GM, Macfarlane G. A meta-analytic investigation of the relationship between the psychological distress of cancer patients and their carers. Social science \& medicine 2005;60(1):1-12.

32. Moser MT, Künzler A, Nussbeck F, Bargetzi M, Znoj HJ. Higher emotional distress in female partners of cancer patients: prevalence and patient-partner interdependencies in a 3-year cohort. Psycho-Oncology 2013; 22(12):2693-2701.

33. Thomas C, Morris SM, Harman JC. Companions through cancer: The care given by informal carers in cancer contexts. Social Science and Medicine 2002; 54: 529-544.

34. Eskelinen M, Korhonen R, Selander T, Ollonen P. The relation of hopelessness/helplessness versus Beck Depression Inventory (BDI) in healthy 
Psychological distress in carers

individuals and in patients with benign breast disease and breast cancer: a prospective case-control study in Finland. Anticancer Research 2015; 35: 941-948.

35. Cosco TD, Doyle F, Ward M, McGee H. Latent structure of the hospital anxiety and depression scale: a 10 year systematic review. Journal of Psychosomatic Research; 72(3): 180-184.

36. Coyne JC, van Sonderen E. The Hospital Anxiety and Depression Scale (HADS) is dead, but like Elvis, there will still be citings. Journal of Psychosomatic Research 2012; 73(1): 77-78. 
Psychological distress in carers

Table 1. Difference between cluster membership on standardised change scores

\begin{tabular}{|c|c|c|c|c|c|c|c|c|}
\hline & \multicolumn{3}{|c|}{ Mean Difference Scores (SD) } & \multirow[t]{2}{*}{$\mathrm{F}$} & \multirow[t]{2}{*}{$\mathrm{p}$} & \multicolumn{3}{|c|}{$\begin{array}{l}\text { Effect sizes for between group } \\
\text { differences (Cohen's d) }\end{array}$} \\
\hline & $\begin{array}{c}\text { Cluster } \\
1 \\
\mathrm{n}=79\end{array}$ & $\begin{array}{c}\text { Cluster } \\
2 \\
n=26\end{array}$ & $\begin{array}{c}\text { Cluster } \\
3 \\
n=66\end{array}$ & & & $1 \& 2$ & $1 \& 3$ & $2 \& 3$ \\
\hline HADS-Anxiety & $\begin{array}{l}0.25 \\
(0.85)\end{array}$ & $\begin{array}{l}-0.40 \\
(0.81)\end{array}$ & $\begin{array}{l}-0.14 \\
(1.15)\end{array}$ & 5.512 & .005 & $-0.77 * *$ & -0.39 & 0.24 \\
\hline HADS-Depression & $\begin{array}{c}0.23 \\
(0.92)\end{array}$ & $\begin{array}{l}-0.37 \\
(0.90)\end{array}$ & $\begin{array}{l}-0.13 \\
(1.08)\end{array}$ & 4.617 & .011 & $-0.66^{*}$ & -0.36 & 0.23 \\
\hline Fear of Recurrence & $\begin{array}{l}0.15 \\
(1.01)\end{array}$ & $\begin{array}{c}0.09 \\
(0.89)\end{array}$ & $\begin{array}{l}-0.22 \\
(1.01)\end{array}$ & 2.573 & .079 & & & \\
\hline $\begin{array}{l}\text { CCQ-Reflection/ } \\
\text { relaxation }\end{array}$ & $\begin{array}{c}0.21 \\
(0.97)\end{array}$ & $\begin{array}{l}-0.29 \\
(0.98)\end{array}$ & $\begin{array}{l}-0.14 \\
(1.01)\end{array}$ & 3.688 & .027 & & & \\
\hline $\begin{array}{l}\text { CCQ-Positive } \\
\text { focus }\end{array}$ & $\begin{array}{l}-0.09 \\
(0.99) \\
\end{array}$ & $\begin{array}{c}0.01 \\
(1.32) \\
\end{array}$ & $\begin{array}{c}0.11 \\
(0.96) \\
\end{array}$ & .710 & .493 & & & \\
\hline CCQ-Diversion & $\begin{array}{c}0.07 \\
(0.88)\end{array}$ & $\begin{array}{l}-0.10 \\
(1.26)\end{array}$ & $\begin{array}{l}-0.05 \\
(1.03)\end{array}$ & .400 & .671 & & & \\
\hline CCQ-Planning & $\begin{array}{c}0.08 \\
(1.05)\end{array}$ & $\begin{array}{c}0.01 \\
(0.98) \\
\end{array}$ & $\begin{array}{l}-0.10 \\
(0.96) \\
\end{array}$ & .580 & .561 & & & \\
\hline CCQ-Interpersonal & $\begin{array}{c}0.09 \\
(1.06)\end{array}$ & $\begin{array}{l}-0.35 \\
(0.71)\end{array}$ & $\begin{array}{c}0.03 \\
(1.00)\end{array}$ & 2.001 & .138 & & & \\
\hline $\begin{array}{l}\text { IPQ-Acute/chronic } \\
\text { timeline }\end{array}$ & $\begin{array}{c}0.05 \\
(0.98)\end{array}$ & $\begin{array}{l}0.46 \\
(0.63)\end{array}$ & $\begin{array}{l}-0.24 \\
(1.08)\end{array}$ & 5.046 & .007 & $0.46^{*}$ & -0.29 & $-0.72 * *$ \\
\hline $\begin{array}{l}\text { IPQ-Cyclical } \\
\text { timeline }\end{array}$ & $\begin{array}{c}0.14 \\
(1.03)\end{array}$ & $\begin{array}{l}-0.75 \\
(0.71)\end{array}$ & $\begin{array}{c}0.12 \\
(0.94)\end{array}$ & 9.366 & $<.001$ & $-0.92 * * *$ & -0.02 & $0.99 * * *$ \\
\hline $\begin{array}{l}\text { IPQ-Treatment } \\
\text { control }\end{array}$ & $\begin{array}{l}-0.15 \\
(0.86)\end{array}$ & $\begin{array}{l}-0.61 \\
(1.29)\end{array}$ & $\begin{array}{c}0.43 \\
(0.85)\end{array}$ & 13.556 & $<.001$ & -0.468 & $0.677 * * *$ & $1.048^{* * *}$ \\
\hline $\begin{array}{l}\text { IPQ-Emotional } \\
\text { cause }\end{array}$ & $\begin{array}{c}0.60 \\
(0.88) \\
\end{array}$ & $\begin{array}{l}-0.26 \\
(0.92) \\
\end{array}$ & $\begin{array}{l}-0.62 \\
(0.71) \\
\end{array}$ & 40.510 & $<.001$ & $-0.97 * * *$ & $-1.51 * * *$ & -0.46 \\
\hline $\begin{array}{l}\text { IPQ-Behavioural } \\
\text { cause }\end{array}$ & $\begin{array}{c}0.43 \\
(0.97)\end{array}$ & $\begin{array}{l}-0.13 \\
(0.80)\end{array}$ & $\begin{array}{l}-0.47 \\
(0.88)\end{array}$ & 17.785 & $<.001$ & $-0.61 *$ & $-0.97 * * *$ & -0.39 \\
\hline $\begin{array}{l}\text { IPQ-Externalised } \\
\text { cause }\end{array}$ & $\begin{array}{c}0.47 \\
(0.76) \\
\end{array}$ & $\begin{array}{l}-0.31 \\
(0.87) \\
\end{array}$ & $\begin{array}{l}-0.44 \\
(1.06) \\
\end{array}$ & 20.078 & $<.001$ & $-0.98 * *$ & $-1.00 * * *$ & -0.13 \\
\hline $\begin{array}{l}\text { IPQ-Consequences } \\
\text { for Patient }\end{array}$ & $\begin{array}{c}0.30 \\
(0.81) \\
\end{array}$ & $\begin{array}{l}-0.29 \\
(0.76) \\
\end{array}$ & $\begin{array}{l}-0.25 \\
(1.18) \\
\end{array}$ & 7.261 & .001 & $-0.75^{* *}$ & $-0.55 * *$ & -0.04 \\
\hline $\begin{array}{l}\text { IPQ-Consequences } \\
\text { for Carer }\end{array}$ & $\begin{array}{c}0.29 \\
(1.02) \\
\end{array}$ & $\begin{array}{l}-0.21 \\
(0.85) \\
\end{array}$ & $\begin{array}{l}-0.26 \\
(0.95) \\
\end{array}$ & 6.360 & .002 & $-0.51 *$ & $-0.55^{* *}$ & -0.05 \\
\hline $\begin{array}{l}\text { IPQ-Personal } \\
\text { control of Patient }\end{array}$ & $\begin{array}{l}-0.07 \\
(0.87)\end{array}$ & $\begin{array}{l}-1.11 \\
(0.72)\end{array}$ & $\begin{array}{c}0.53 \\
(0.85)\end{array}$ & 35.837 & $<.001$ & $-1.24 * * *$ & $0.70 * * *$ & $2.01 * * *$ \\
\hline $\begin{array}{l}\text { IPQ-Personal } \\
\text { control of Carer }\end{array}$ & $\begin{array}{l}-0.15 \\
(0.75)\end{array}$ & $\begin{array}{l}-0.85 \\
(1.19)\end{array}$ & $\begin{array}{c}0.51 \\
(0.90)\end{array}$ & 24.067 & $<.001$ & $-0.81^{*}$ & $0.80 * * *$ & $1.38 * * *$ \\
\hline $\begin{array}{l}\text { IPQ-Illness } \\
\text { coherence of } \\
\text { Patient }\end{array}$ & $\begin{array}{l}-0.14 \\
(0.87)\end{array}$ & $\begin{array}{c}0.70 \\
(1.35)\end{array}$ & $\begin{array}{l}-0.11 \\
(0.88)\end{array}$ & 8.222 & $<.001$ & $0.83 *$ & -0.01 & $-0.82 *$ \\
\hline $\begin{array}{l}\text { IPQ-Illness } \\
\text { coherence of Carer }\end{array}$ & $\begin{array}{l}-0.47 \\
(0.91) \\
\end{array}$ & $\begin{array}{l}1.13 \\
(0.84)\end{array}$ & $\begin{array}{c}0.11 \\
(0.74)\end{array}$ & 36.132 & $<.001$ & $1.78 * * *$ & $0.69 * * *$ & $-1.32 * * *$ \\
\hline $\begin{array}{l}\text { Bonferroni correction } \\
\text { Effect size is d Cohen } \\
* \mathrm{p}<0.05, * * \mathrm{p}<0.01,\end{array}$ & $\begin{array}{l}\text { plied to } \mathrm{si} \\
\text { adjusted } \mathrm{f}\end{array}$ & $\begin{array}{l}\text { ificance v } \\
\text { varied sa }\end{array}$ & $\begin{array}{l}\text { ues for } \mathrm{AI} \\
\text { le sizes }\end{array}$ & VA at 0. & level. & & & \\
\hline
\end{tabular}


Psychological distress in carers

Table 2. Regression analysis with change in fear of recurrence as the outcome variable

\begin{tabular}{|l|l|l|l|l|}
\hline & $\begin{array}{l}\text { Unstandardized } \\
\text { regression } \\
\text { coefficient }\end{array}$ & $\mathbf{t}$ & $\mathbf{p}$ & $\begin{array}{l}\text { Standardized } \\
\text { regression } \\
\text { coefficient }\end{array}$ \\
\hline Age & -.005 & 0.424 & .672 & -.053 \\
\hline Gender & -.058 & -.297 & .767 & -.026 \\
\hline $\begin{array}{l}\text { Number of } \\
\text { months since } \\
\text { diagnosis }\end{array}$ & -.001 & -.715 & .476 & -.059 \\
\hline $\begin{array}{l}\text { Other illnesses } \\
\text { or medical } \\
\text { conditions }\end{array}$ & -.179 & -1.123 & .263 & -.090 \\
\hline CCQ-Planning & -.052 & -.510 & .611 & -.052 \\
\hline $\begin{array}{l}\text { CCQ- } \\
\text { Interpersonal }\end{array}$ & .218 & 2.326 & .021 & .218 \\
\hline $\begin{array}{l}\text { CCQ- } \\
\text { Relaxation }\end{array}$ & .003 & .028 & .978 & .003 \\
\hline $\begin{array}{l}\text { CCQ-Positive } \\
\text { focus }\end{array}$ & -.010 & -.105 & .916 & -.010 \\
\hline $\begin{array}{l}\text { CCQ- } \\
\text { Diversionary }\end{array}$ & -.051 & -.518 & .605 & -.051 \\
\hline $\begin{array}{l}\text { IPQR-Cluster 2 } \\
\text { versus Cluster } \\
\mathbf{1}\end{array}$ & .022 & .093 & .926 & .008 \\
\hline $\begin{array}{l}\text { IPQR-Cluster 3 } \\
\text { versus Cluster } \\
\mathbf{1}\end{array}$ &.- .419 & -2.282 & .024 & -205 \\
\hline Constant & .759 & .819 & & \\
\hline
\end{tabular}

Step $1 \mathrm{R}^{2}=.092, \mathrm{R}^{2}$ adj $=-.016$. Step $2 \mathrm{R}^{2}=.163, \mathrm{R}^{2}$ adj $=.019$ 
Psychological distress in carers

Table 3. Regression analysis with change in depression as the outcome variable

\begin{tabular}{|l|l|l|l|l|}
\hline & $\begin{array}{l}\text { Unstandardized } \\
\text { regression } \\
\text { coefficient }\end{array}$ & $\mathbf{t}$ & $\mathbf{p}$ & $\begin{array}{l}\text { Standardized } \\
\text { regression } \\
\text { coefficient }\end{array}$ \\
\hline Age & -.010 & -.840 & .402 & -.099 \\
\hline Gender & -.043 & -.235 & .814 & -.019 \\
\hline $\begin{array}{l}\text { Number of } \\
\text { months since } \\
\text { diagnosis }\end{array}$ & .00009449 & .061 & .952 & .005 \\
\hline $\begin{array}{l}\text { Other illnesses } \\
\text { or medical } \\
\text { conditions }\end{array}$ & -.161 & -1.079 & .282 & -.081 \\
\hline CCQ-Planning & .169 & 1.785 & .076 & .169 \\
\hline $\begin{array}{l}\text { CCQ- } \\
\text { Interpersonal }\end{array}$ & .128 & 1.454 & .148 & .128 \\
\hline $\begin{array}{l}\text { CCQ- } \\
\text { Relaxation }\end{array}$ & -.049 & -.505 & .614 & -.049 \\
\hline $\begin{array}{l}\text { CCQ-Positive } \\
\text { focus }\end{array}$ & -.243 & -2.802 & .006 & -.243 \\
\hline $\begin{array}{l}\text { CCQ- } \\
\text { Diversionary }\end{array}$ & .101 & 1.081 & .281 & .101 \\
\hline $\begin{array}{l}\text { IPQR-Cluster 2 } \\
\text { versus Cluster } \\
\mathbf{1}\end{array}$ &.- .494 & -2.197 & .030 & -.178 \\
\hline $\begin{array}{l}\text { IPQR-Cluster 3 } \\
\text { versus Cluster } \\
\mathbf{1}\end{array}$ &.- .375 & -2.177 & .031 & -270 \\
\hline Constant & .960 & 1.106 & -183 \\
\hline
\end{tabular}

Step $1 \mathrm{R}^{2}=.132, \mathrm{R}^{2}$ adj $=.029$. Step $2 \mathrm{R}^{2}=.264, \mathrm{R}^{2}$ adj $=.137$ 
Psychological distress in carers

Table 4. Regression analysis with change in anxiety as the outcome variable

\begin{tabular}{|l|l|l|l|l|}
\hline & $\begin{array}{l}\text { Unstandardized } \\
\text { regression } \\
\text { coefficient }\end{array}$ & $\mathbf{t}$ & $\mathbf{p}$ & $\begin{array}{l}\text { Standardized } \\
\text { regression } \\
\text { coefficient }\end{array}$ \\
\hline Age & -.021 & -1.919 & .057 & -.208 \\
\hline Gender & -.323 & -1.931 & .055 & -.145 \\
\hline $\begin{array}{l}\text { Number of } \\
\text { months since } \\
\text { diagnosis }\end{array}$ & .000 & .145 & .885 & .010 \\
\hline $\begin{array}{l}\text { Other illnesses } \\
\text { or medical } \\
\text { conditions }\end{array}$ & -.108 & -.782 & .436 & -.054 \\
\hline CCQ-Planning & -.048 & -.552 & .582 & -.048 \\
\hline $\begin{array}{l}\text { CCQ- } \\
\text { Interpersonal }\end{array}$ & .128 & 1.578 & .117 & .128 \\
\hline $\begin{array}{l}\text { CCQ- } \\
\text { Relaxation }\end{array}$ & .234 & 2.613 & .010 & .234 \\
\hline $\begin{array}{l}\text { CCQ-Positive } \\
\text { focus }\end{array}$ & -.173 & -2.163 & .032 & -.173 \\
\hline $\begin{array}{l}\text { CCQ- } \\
\text { Diversionary }\end{array}$ & .283 & 3.301 & .001 & .283 \\
\hline $\begin{array}{l}\text { IPQR-Cluster 2 } \\
\text { versus Cluster } \\
\mathbf{1}\end{array}$ &.- .397 & -1.912 & 0.58 & -.143 \\
\hline $\begin{array}{l}\text { IPQR-Cluster 3 } \\
\text { versus Cluster } \\
\mathbf{1}\end{array}$ & -.298 & -1.878 & .062 & .028 \\
\hline Constant & 1.782 & 2.225 & -146 \\
\hline
\end{tabular}

Step $1 \mathrm{R}^{2}=.122, \mathrm{R}^{2}$ adj $=.018$. Step $2 \mathrm{R}^{2}=.374, \mathrm{R}^{2}$ adj $=.266$ 